\title{
DESIGN AND SIMULATION OF XZ MEMS MICROPOSITIONING WITH 3D-COMPLEX STRUCTURE
}

\author{
Tachadol Suthisomboon ${ }^{1}$, Sylwester Bargiel ${ }^{2}$, Kanty Rabenorosoa ${ }^{2}$, and Eakkachai Pengwang ${ }^{1}$ \\ ${ }^{1}$ Institute of Field Robotics (FIBO), King Mongkut's University of Technology Thonburi \\ (KMUTT), Bangkok, Thailand \\ ${ }^{2}$ FEMTO-ST, University of Bourgogne Franche-Comté (UBFC), CNRS, Besançon, France
}

\begin{abstract}
Micropositioning systems are widely used in many applications, for example, optical industry, medical devices, and micro-assembly applications. Commonly, MEMS-based micropositioning systems use the conventional fabrication technique such as lithography, etching, and thin-film processes. However, typical microfabrication process is challenging to fabricate 3dimensional complex device by using the masking and etching operations. This research presents a novel design of 3D micropositioning system with electrostatic combdrives with the new converting mechanism. The device can convert the in-plane motion to out-of-plane movement. The proposed design is possible by using FEMTOPRINT $^{\circledR}$ which combines material modification by femtosecond laser-beam and chemical etching. The results from the simulation shown that the 3D-complex micropositioning system can achieve a wide range of workspace up to $1,212.79 \mu \mathrm{m}^{2}$. In $\mathrm{X}$-axis and Z-axis, it can translate up to a maximum displacement of $33.34 \mu \mathrm{m}$ and $72.73 \mu \mathrm{m}$ respectively, while the footprint of the device is $1.65 \times 1.10$ $\mathrm{mm}^{2}$. This device can be a new type of MEMS basedmicropositioning system, named "glassy MEMS" that is suitable for 3D-complex mechanism and can be used in many applications.
\end{abstract}

\section{KEYWORDS}

XZ-micropositioning; MEMS; Femtoprint Machine; FEA Simulation; Electrostatic comb-drive.

\section{EXTENDED ABSTRACT}

Micropositioning and micromanipulation systems are required for a variety of applications on such as microsurgery [1], micro-assembly [2] and microscopy [3]. Optical-assisted surgery for medical device, optical packaging, and micropositioning in SEM are examples of this development. Recently, Micro-electro-mechanical system (MEMS) are commonly fabricated by using a process of lithography, etching, thin-film deposition. The complications of the fabrication process are varied for different designs and materials. However, there are several attempts to ease the fabrication processes in order to complete the novel 3D-mechanism. For one example, the femtosecond laser-assisted chemical etching has been investigated as an alternative process to fabricate microdevices without a lithography mask. The wavelength of the laser beam is utilised to change the properties of the silica materials. This method led to rapid development on fabricating 3D micro-devices [4]-[6].

Recently, the development of MEMS micro-actuators is mainly on $2 \mathrm{D}$. The $2 \mathrm{D}$ electrostatic actuator is a common type of actuator in XY-micropositioning. On the other hand, the thermal actuator, especially bi-morph type is commonly used in the micropositioning that requires out-of-plane motion. The fabrication of thermal actuators is typically implemented in the 2D structure. Then, the motion are controlled by the difference on thermal expansion coefficient between two material. However, now there is an alternative way to fabricate complex 3D structure more efficiently and less complexity. The Femtoprint machine is an example of this fabrication process. This method can be implemented with conventional electrostatic comb-drives to control the mechanism in an out-of-plane direction. However, scientists and engineers are required for preparing a good design with simulation to validate the structure before starting the process.

In this work, 3D complex structure micropositioning consists of cross-axis flexure slant pivot, electrostatic comb drive arrays, leaf spring, and platform, which can be described in Figure 1. The design focused on the compactness and feasibility to fabricate with the Femtoprint machine. Moreover, the critical dimensions were summarized in Table 1. To create an out-of-plane motion, the cross-axis flexural slant pivot acts as a compliant mechanism in the microscale. The thickness of the flexure was limited by the fabrication process. Because the wet etching or the ultrasonic bath may destroy the structure of flexure slant. Then, the thickness and overall dimension are considered from the process. These parameters and combdrive dimension were shown in Figure 2.

Simulations of the device were done by using Ansys ${ }^{\circledR}$. The displacement and equivalent stress were evaluated by a static tool. The result showed (in Figure 3) that the maximum displacement in the $\mathrm{z}$-axis is $72.73 \mu \mathrm{m}$, while the actuator moves $30.95 \mu \mathrm{m}$ in the transverse direction. Moreover, the maximum equivalent stress is $143.8 \mathrm{MPa}$ on the leaf spring. The modal analysis also showed the first two mode shapes are $1.46 \mathrm{kHz}$ and $2.04 \mathrm{kHz}$, which represent torsion in flexure slanted leaf spring in $\mathrm{Y}$ and $\mathrm{X}$-axis respectively.

The simulation result also showed that the micropositioning create a $1,212.79 \mu \mathrm{m}^{2}$ working area with $1.83 \mathrm{~mm}^{2}$ footprint area. To compare with the previous research, this design can create a suitable dimensionless ratio of the workspace area divided by the footprint area. The results of this work and previous work are showed in Table 2. Next step, this design will be fabricated and evaluated with the experiments, compared with these simulation results.

\section{CONTACT}

* Tachadol Suthisomboon, Tachadol.s@mail.kmutt.ac.th 


\section{REFERENCES}

[1] E. Pengwang, K. Rabenorosoa, M. Rakotondrabe, and N. Andreff, "Characterization and micro-assembly of electrostatic actuators for 3-DOF micromanipulators in laser phonomicrosurgery," in 2014 IEEE/ASME 10th Intl. Conf. Mechatronic and Embedded Systems and Applications (MESA), Senigallia, Italy, pp. 1-6, 2014.

[2] Q. X. Zhang et al., "A silicon platform with MEMS active alignment function and its potential application in Si-Photonics packaging," IEEE J. Sel. Top. Quantum Electron., vol. 16, no. 1, pp. 267-275, 2010.

[3] G. Xue, M. Toda, and T. Ono, "Comb-Drive XYZmicrostage with large displacements based on Chip-Level microassembly," J. Microelectromechanical Syst., vol. 25, no. 6, pp. 989-998, 2016.

[4] F. He et al., "Femtosecond laser fabrication of monolithically integrated microfluidic sensors in glass," Sensors, vol. 14, no. 10, pp. 19402-19440, 2014.

[5] B. Lenssen and Y. Bellouard, "Optically transparent glass micro-actuator fabricated by femtosecond laser exposure and chemical etching," Appl. Phys. Lett., vol. 101, no. 10, p. 103503, 2012.

[6] V. Tielen and Y. Bellouard, "Three-Dimensional Glass Monolithic Micro-Flexure Fabricated by Femtosecond Laser Exposure and Chemical Etching," Micromachines, vol. 5, no. 3, pp. 697-710, 2014.

[7] X. Zhang, L. Zhou, and H. Xie, "A large range microXZ-stage with monolithic integration of electrothermal bimorph actuators and electrostatic comb drives," in 2016 IEEE 29th Intl. Conf. Micro Electro Mechanical Systems (MEMS), Shanghai, China, pp. 71-74, 2016.

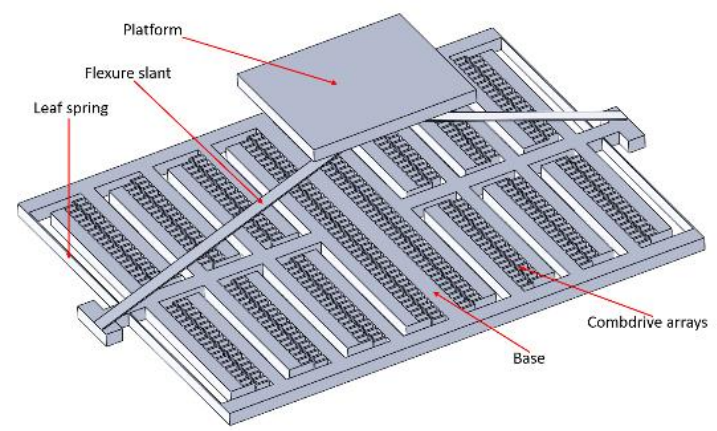

Figure 1: Components of this micropositioning system design.

\begin{tabular}{|l|l|}
\hline \multicolumn{1}{|c|}{ Component } & \multicolumn{1}{|c|}{ Size } \\
\hline $\begin{array}{l}\text { Overall } \\
\text { dimension }\end{array}$ & $\begin{array}{l}\text { Overall: } 1656(\mathrm{~L}), 1106(\mathrm{~W}), 500(\mathrm{H}) \\
\mu \mathrm{m}\langle\mathrm{x}, \mathrm{y}, \mathrm{z}\rangle\end{array}$ \\
& Base: $1656,1106,40 \mu \mathrm{m}(\mathrm{t})<\mathrm{x}, \mathrm{y}, \mathrm{z}\rangle$ \\
\hline Flexure slant & $\begin{array}{l}\text { Length: } 1146.76 \mu \mathrm{m} \\
\text { Width: } 40 \mu \mathrm{m}\end{array}$ \\
\hline
\end{tabular}

\begin{tabular}{|l|l|}
\hline & $\begin{array}{l}\text { Thickness: } 4 \mu \mathrm{m} \\
\text { Angle: } 21.48 \text { degrees }\end{array}$ \\
\hline $\begin{array}{l}\text { Comb-drive } \\
\text { (See on fig.2) }\end{array}$ & $\begin{array}{l}\text { Number of fingers }(\mathrm{n}): 148 \text { fingers per } \\
\text { side } \\
\text { Gap }\left(g_{c d}\right): 6 \mu \mathrm{m} \\
\text { Thickness }(t): 40 \mu \mathrm{m} \\
\text { Finger width }\left(w_{c d}\right): 6 \mu \mathrm{m} \\
\text { Finger length }\left(l_{c d}\right): 40 \mu \mathrm{m} \\
\text { Finger overlap }\left(o_{c d}\right): 8 \mu \mathrm{m}\end{array}$ \\
\hline $\begin{array}{l}\text { Leaf spring } \\
\text { (See on fig.2) }\end{array}$ & $\begin{array}{l}\text { Length }\left(l_{l s}\right): 478 \text { microns } \\
\text { Thickness }(t): 40 \text { microns } \\
\text { Width }\left(w_{l s}\right): 4 \text { microns }\end{array}$ \\
\hline Platform & $500,400,40$ microns $<\mathrm{x}, \mathrm{y}, \mathrm{z}>$ \\
\hline
\end{tabular}

Table 1: Dimension of the micropositioning system.

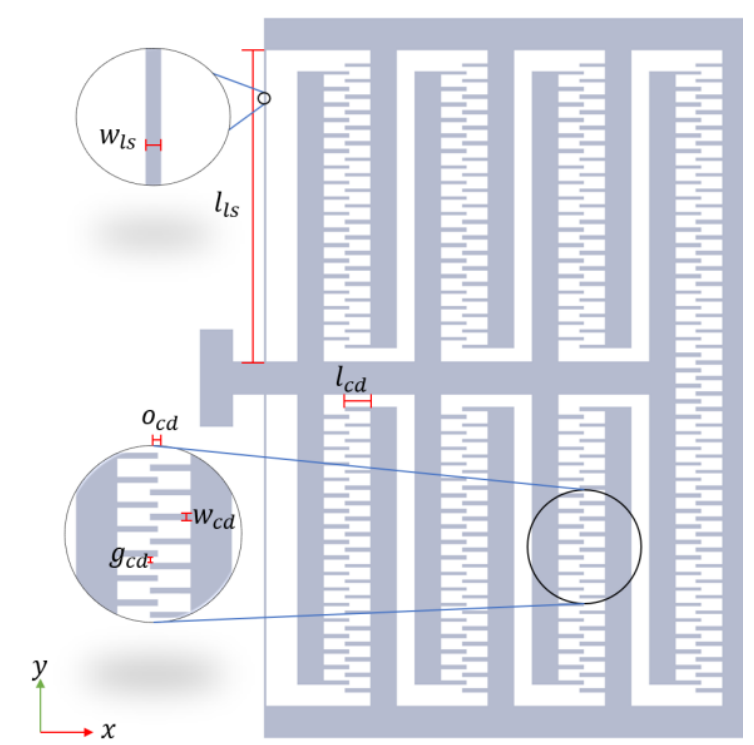

Figure 2: Comb-drive and leaf spring dimensions.

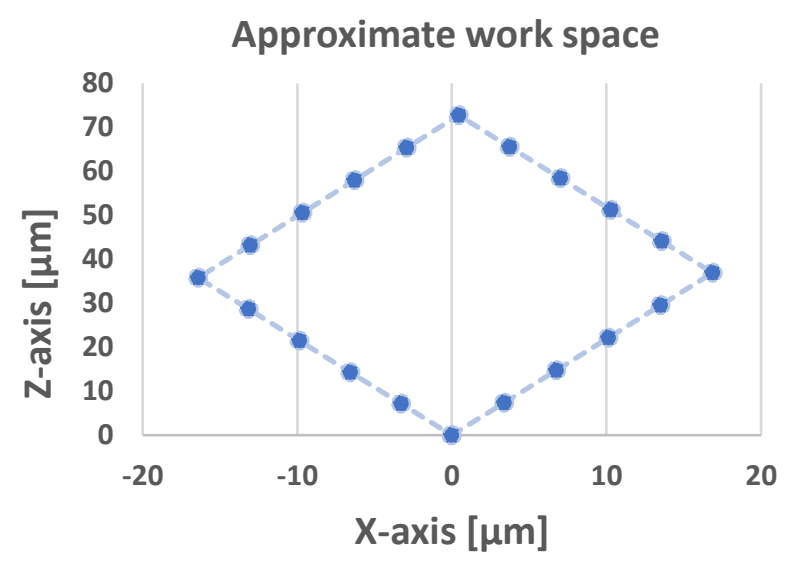

Figure 3:Approximate work space of the proposed XZmicropositioning system.

\begin{tabular}{|l|l|l|l|l|l|}
\hline \multicolumn{1}{|c|}{ Publication } & \multicolumn{1}{|c|}{ Actuator \& Materials } & Workspace & Footprint & $\begin{array}{c}\text { Dimensionless } \\
\text { Ratio }\end{array}$ & $\begin{array}{c}\text { First } \\
\text { resonance } \\
\text { frequency }\end{array}$ \\
\hline This project & 2 set of bi-directional comb drive & $1,212.79 \mu \mathrm{m}^{2}$ & $1.83 \mathrm{~mm}^{2}$ & 662.00 & $1467 \mathrm{~Hz}$ \\
\hline X. Zhang, 2016[7] & $\begin{array}{l}\text { Thermal actuator bimorph and bi- } \\
\text { directional comb drive }\end{array}$ & $4,284 \mu \mathrm{m}^{2}$ & $22.26 \mathrm{~mm}^{2}$ & 192.45 & $\begin{array}{l}447 \mathrm{~Hz} \\
\text { (in-plane) }\end{array}$ \\
\hline
\end{tabular}

Table 2: comparisons on this study and previous work. 